\title{
LAS CONDICIONES DE VIDA DURANTE EL PRIMER FRANQUISMO. EL CASO DE LAS ISLAS BALEARES
}

por

\author{
DAVID GINARD I FERÓN
}

Universitat de les Illes Balears

RESUMEN: $\quad$ Entre 1939 y 1951 la mayor parte de la población de las Islas Baleares conoció una fuerte regresión de sus condiciones de vida, que resulta sorprendente dada la relativa bonanza económica de las décadas precedentes y el limitado impacto del conflicto bélico de 1936-39 en el aparato productivo isleño. A partir del estudio de diversas fuentes (en particular, informes elaborados por el Instituto Nacional de Estadística, el Gobierno Civil, la Diputación Provincial, las Cámaras de Comercio, la Jefatura Provincial de Falange y algunos ayuntamientos) se analizan aspectos tales como la desfavorable evolución de la relación entre precios y salarios, la extensión de la corrupción económica, y la degradación del abastecimiento popular, de la sanidad, de la vivienda y de la educación. La peculiar estructura productiva de las Baleares — caracterizada entonces por el predominio de la industria de bienes de consumo y de la agricultura de exportación - es una de las principales causas que explican la especial repercusión que tuvo en este archipiélago la crisis económica general de la posguerra española.

PALABRAS CLAVE: Autarquía. Intervencionismo. Racionamiento. Inflacción. Estraperlo

ABSTRACT: From 1939 to 1951 the majority of the inbabitants of the Balearic Islands suffered a sharp decline in standards of living, which seems surprising when taking into account the relative economic boom of the previous decades and the reduced impact of the 1936-1939 war on the production system. Using a varied range of sources, particularly reports from the National Institute of Statistics, the Civil Government, the regional Parliament, Chambers of Commerce, the regional Falange beadquarters and a number of municipal governments, a series of variables such as the unfavourable price-income relationship, the increase in levels of economic corruption, and the decline of basic daily supplies, bealth provision, bousing and education bave been analysed. The peculiar production system of the Balearic

Hispania, LXII/3, núm. 212 (2002) 1099-1128 
Islands, characterized at that time by the predominance of the consumer goods industry and export of agricultural produce, is one of the main reasons explaining the far-reaching effects of the general post-war economic crisis on to the Balearic archipelago.

KEY WORDS: Autarchy. Economic interventionism. Inflation. Black market.

Durante los años de la Guerra Civil, el bando nacional se esforzó por convencer a la población de las dos zonas contendientes de su aplastante superioridad en el terreno de la eficacia económica. Frente a una España roja en la que el hambre constituía una realidad pavorosa, la España de Franco habría conseguido superar las inevitables consecuencias del estallido bélico sobre la actividad económica y establecer un aparato productivo eficiente que permitía a la mayoría de la población satisfacer sus necesidades básicas. Episodios como el lanzamiento de pan sobre Madrid por parte de la aviación franquista constituyen, más allá de su significado propagandístico, un buen ejemplo del innegable éxito relativo que los alzados contra la República tuvieron en este ámbito, y que sin duda representa una de las principales razones de su victoria. Hay que tener en cuenta que el bando franquista contó, desde el principio, con la enorme ventaja de disponer del control de la práctica totalidad de las producciones agrarias básicas. Ello, unido a su capacidad para establecer un control centralizado de los recursos dirigido al objetivo exclusivo de ganar la guerra, explicaría en buena parte su mayor capacidad para asegurar el aprovisionamiento de alimentos. ${ }^{1}$. No ha de sorprender, por tanto, que tras la derrota gubernamental muchos españoles creyeran de buena fe que se había iniciado una nueva era en la que desaparecerían para siempre las privaciones, incluida la detestable cartilla de racionamiento, «esa señal infamante del período rojo, vestigio de socialización»².

1 Recordemos, por ejemplo, que un informe del economista franquista Higinio París Aguilar elaborado en 1940 indicaba que durante la guerra la extensión de superficie sembrada de trigo se había reducido en un $30 \%$ en la zona republicana y tan sólo un $10 \%$ en la zona nacional (Documentos inéditos para la Historia del Generalísimo Franco, tomo II-1, Fundación Nacional Francisco Franco, Madrid: 1992, pág. 333). Cf. BARCIELA LóPEZ, C.: «Producción y política cerealista durante la guerra civil española (1936-1939)», en Historia económica y pensamiento social, Alianza, Madrid: 1983, pág. 653-663; BRICALL, J.M.: «La economía española (1936-1939)» en La Guerra Civil Española. 50 años después, Labor, Barcelona: 1986, pág. 377-378; MALEFAKIS, E.: «La economía española y la Guerra Civil» en La economía española del siglo XX. Una perspectiva bistórica, Ariel, Madrid: 1987, pág. 159). La bibliografía sobre la evolución económica durante la Guerra Civil continúa siendo muy escasa. Una síntesis reciente en: SÁNCHEZ ASIÁIN, J.A: Economía y finanzas en la Guerra Civil española (1936-1939), Real Academia de la Historia, Madrid: 1999.

2 ABELlA, R.: Por el imperio hacia Dios. Crónica de una postguerra (1939-1955), Planeta, Barcelona: 1978, pág. 13. De manera significativa, todavía en 1942, un editorial del órgano de la Comisaría General de Abastecimientos y Transportes atribuía los problemas de suministro alimenticio que se padecían entonces a la extensión a la España nacional de las prácticas corruptas de la zona

Hispania, LXII/3, núm. 212 (2002) 1099-1128 
Sin embargo, en contraposición con el idílico panorama de pan, trabajo y justicia que las autoridades franquistas prometían para la Nueva España nacida el 1 de abril de 1939, durante los años cuarenta la economía española sufrió una brutal recesión, que incluso sobrecogió a los observadores extranjeros en una época en la que todo el continente padecía graves dificultades. Lejos de desaparecer, el racionamiento de productos básicos —establecido en mayo de 1939 alcanzó unas dimensiones jamás conocidas en la historia de España. Como es sabido, el régimen atribuyó esta crisis a las destrucciones ocasionadas por la Guerra Civil y a los trastornos comerciales provocados por la Segunda Guerra Mundial, pero la realidad es que la ineficiencia de la política autárquica e intervencionista del régimen franquista se llevó la mayor parte de la responsabilidad ${ }^{3}$.

Una de las repercusiones más evidentes de la violenta recesión de la posguerra, fue un hundimiento de las condiciones de vida de la clase trabajadora que no tiene parangón en la historia contemporánea de España y que ha sido objeto en los últimos años de numerosos trabajos de ámbito estatal y territorial $^{4}$. El presente artículo pretende ofrecer una aproximación al estudio de las

republicana: «En la llamada Zona Nacional se implantó una adecuada distribución de víveres con arreglo a un complicado plan de abastecimiento, que servirá de modelo en los estudios económicos y especialmente en los pronoéticos. La cooperación del público, el clima moral de la España Nacional y el sano entusiasmo por alcanzar la victoria económica, fueron las causas que contribuyeron a mantener un justo equilibrio en el abastecimiento y un nivel adecuado en los precios [...]. La victoria, al unir las dos zonas, fue aprovechada por los enemigos de España para extender las lacras de la zona roja, cuyos procedimientos nefastos prendieron en todas las almas ruines. Ocultación y ustraperlismo» fueron las causas, entre otras, que destruyeron el equilibrio económico, y el mercado negro impuso sus trágicos zarpazos sobre las clases humildes» (« $\mathrm{El}$ racionamiento y la cartilla individual», Alimentación Nacional 4 (15 de abril de 1942), pág. 3).

3 Cf., por ejemplo, CARreras, A.: «Depresión económica y cambio estructural durante el decenio bélico (1936-1945)», en GARCÍA DELGADO, J. L. (ed.): El primer franquismo. España durante la Segunda Guerra Mundial, Siglo XXI, Madrid: 1989, pág. 3-33; CATALÁN, J.: La economía española y la Segunda Guerra Mundial, Ariel, Barcelona: 1995. Una buena síntesis reciente sobre la evolución de la economía española durante el franquismo en BARCiela, C. - LóPEZ, M $^{\text {a }}$. I. - MELGRALEjo, J. - Miranda, J.A.: La España de Franco (1939-1975). Economía, Síntesis, Madrid: 2001.

4 Cf., en especial, Molinero, C. - Ysàs, P.: «Patria, justicia y pan». Nivell de vida $i$ condicions de treball a Catalunya 1939-1951, La Magrana, Barcelona: 1985; Id, Productores disciplinados y minorías subversivas. Clase obrera y conflictividad laboral en la España franquista, Siglo XXI, Madrid 1998; BABIANO, J.: Paternalismo industrial y disciplina fabril en España (1938-1958), Consejo Económico y Social, Madrid 1998; RICHARDS, M.: Un tiempo de silencio. La guerra civil y la cultura de la represión en la España de Franco, 1936-1945, Crítica, Barcelona 1999; P. YSÀS: «Les condicions de vida durant la postguerra", en Els anys de la postguerra a Catalunya (1939-1959), Publicacions de l'Abadia de Montserrat, Barcelona: 1994, pág. 7-22; C. MIR, Vivir es sobrevivir. Justicia, orden y marginación en la Cataluña rural de posguerra, Milenio, Lleida: 2000; MORENO FONSERET, R.: La autarquía en Alicante, 1939-1952, Institut de Cultura Juan Gil-Albert, Alicante: 1994; id, «Los costes del franquismo. La economía alicantina durante la postguerra», Canelobre 31/32 (primavera - verano 1995), pág. 7988; Duch Plana, M.: Reus sota el primer franquisme, Associació d'Estudis Reusencs, Reus: 1996, pág. 112-151; EIroa SAn Francisco, M.: Viva Franco. Hambre, racionamiento, falangismo. Málaga, 19391942, edición de la autora, Málaga: 1995, pág. 103-154. Con un carácter más bien periodístico, ABella, R.: Por el imperio hacia Dios. Crónica de una postguerra, op. cit; id.: La vida cotidianá bajo el 
repercusiones sociales del primer franquismo a partir del caso de las Islas Baleares. En primer lugar, analizaremos brevemente la situación económica del archipiélago entre 1939 y 1951, con una especial atención las consecuencias que ésta tuvo sobre las condiciones de trabajo de la clase obrera. Abordaremos a continuación la evolución de los precios y salarios a lo largo de la década, aspecto éste que nos permitirá entender hasta qué punto la caída de la capacidad adquisitiva de los trabajadores determinó sus condiciones de vida. Este apartado tendrá su complemento en el estudio del impacto que tuvo sobre la alimentación de las clases populares el régimen de racionamiento implantado en todo el territorio español desde el final de la contienda, y en el análisis de otros ámbitos importantes de la vida cotidiana como la sanidad, la vivienda y la educación. Finalmente, se ofrecerá una conclusión general.

\section{AUTARQUÍA, INTERVENCIONISMO Y DESEMPLEO}

En el marco de la evolución económica de la España de la posguerra, el caso de las Islas Baleares resulta especialmente significativo. En las dos décadas anteriores a la Guerra Civil, las Baleares habían experimentado un fuerte crecimiento económico que había permitido consolidar un modelo peculiar, en ocasiones asociado al concepto de industrialización difusa, basado en una combinación de una agricultura de exportación muy dinámica y una progresiva implantación de industrias de consumo ${ }^{5}$. Las inevitables perturbaciones que siguieron al estallido bélico de 1936 no tuvieron, en principio, consecuencias dramáticas para las Islas. Mallorca, la isla principal del archipiélago, gozó durante los años de la guerra de una economía relativamente próspera, principalmente debido a la expansión de industrias como las del calzado y el textil que, después de unos primeros meses de paralización, funcionaron a pleno rendimiento. Lejos de conocer las estrecheces de la zona republicana, Mallorca suministró cantidades muy apreciables de material militar y de alimentos al ejército nacional y la población dispuso de unos niveles de abastecimiento bastante satisfactorios ${ }^{6}$. Ciertamente, la situación del resto de las islas fue más

régimen de Franco, Temas de Hoy, Madrid: 1996, pág. 123-135; MARTí GóMEZ, J.: La España del estraperlo (1936-1952), Planeta, Barcelona: 1995, pág. 121-145; LAFUENTE, I.: Tiempos de hambre. Viaje a la España de la posguerra, Temas de Hoy, Madrid: 1999.

5 Cf., en especial, MANERA, C.: Història del creixement econòmic a Mallorca (1700-2000), Lleonard Muntaner Editor, Palma: 2001 y id., «Renta de situación y desarrollo mercantil: el crecimiento económico de Baleares», en Germán, L. - LlOpis, E. - MALUQuer De Motes, J. - ZAPATA, S. (eds.): Historia económica regional de España siglos XIX y XX, Crítica, Barcelona: 2001, pág. 441-475.

$6 \mathrm{Tal}$ y como indicaba un artículo aparecido en una revista agrícola mallorquina pocas semanas antes de la finalización del conflicto, «Mallorca ha demostrado su gran capacidad productora esto[s] dos años y medio de guerra, la agricultura mallorquina y su ganadería y avicultura, han abastecido completamente la isla y aún hemos podido enviar muchísimos productos al resto de España. - La Agricultura mallorqui-

Hispania, LXII/3, núm. 212 (2002) 1099-1128 
compleja. Menorca - la única que permaneció bajo el control gubernamental- se vio afectada por el bloqueo practicado por la marina nacional, conociendo importantes problemas de abastecimiento y una reducción de la producción industrial de entre un $40 \%$ y un $50 \%$ respecto a la existente en $1935^{7}$. Ibiza y Formentera, finalmente, se vieron afectadas por la crisis de empresas tan emblemáticas como las salinas, por lo que padecieron un incremento del paro y precisaron de la ayuda mallorquina para alimentar a su población entre 1937 y $1938^{8}$. Sin embargo, parece claro que, en conjunto, el archipiélago presentaba en 1939 un panorama económico bastante menos difícil que el de la mayor parte del Estado, en buena parte porque las destrucciones del aparato productivo provocadas por el conflicto bélico habían sido de muy escasa consideración (éstas se habían limitado básicamente a los efectos, en general limitados, de los bombardeos, de la expedición republicana a Mallorca, Ibiza y Formentera de agosto - septiembre de 1936, y de la rápida ocupación franquista de Menorca en febrero de 1939).

De todas maneras, durante los años cuarenta las Baleares tuvieron que hacer frente a un hundimiento de la mayor parte de sus índices económicos. Esta evolución económica presenta considerables similitudes con los casos de Cataluña y el País Valenciano, y debe ser explicada en función de la enorme dependencia del archipiélago respecto al comercio exterior y al hecho de que su producción industrial - centrada en bienes de consumo como el calzado, los tejidos o las conservas de alimentos - no fuera considerada de interés nacional

\footnotetext{
na, ha demostrado basta la evidencia su capacidad productora, su cuantiosa riqueza, lo mucho que produce la isla dorada, que después de dejar atendidos a sus moradores bemos logrado con los albaricoques, almendrón, alcaparras, patatas... muchísimas divisas... todo esto se volvía oro, en los momentos difíciles, en los días que más se necesitaba. Estamos orgullosos de ser agricultores y agricultores mallorquines, porque contribuimos en una parte importantísima al triunfo de la Causa.» («Adelante», Mallorca agrícola y avicultura 74 (febrero de 1939), pág. 102.) Para un análisis de la economía mallorquina durante la guerra civil se pueden consultar los trabajos de GAYOSO, P.: «Situació comercial i industrial a Mallorca durant la guerra civil (1936-1939)", en MANERA, C. - PETRUS, J. M.: Del taller a la fábrica. El procés d'industrialització a Mallorca, Ajuntament de Palma, Palma: 1991), pág. 167-179; id., "Conjuntura crítica i activitat comercial a Mallorca 1933-1939", Estudis Baleàrics 53 (1996), pàg. 49-61 y los de GINARD, D.: "Els anys de la fam". Una aproximació a l'economia mallorquina durant la postguerra (19391951)», en Randa. 43 (1999), pág. 123-152 y L'economia balear (1929-1959), Documenta Balear, Palma: 1999. Hay referencias de interés en algunos de los libros de Josep Massot i Muntaner, en particular La Guerra Civil a Mallorca, Publicacions de l'Abadia de Montserrat, Barcelona: 1976 y El cònsol Alan Hillgarth $i$ les Illes Balears (1936-1939), Publicacions de l'Abadia de Montserrat, Barcelona: 1995.

7 Cf. Un resumen general en Murillo, A.: La Guerra Civil a Menorca (1936-1939), Documenta Balear, Palma: 1997. Un buen ejemplo de los problemas de abastecimiento en un municipio menorquín en PONs Coll, G.: San Luis. 35 años de bistoria (Cuarta parte: La Guerra Civil), edicions Llevant, Sant Lluís: 1998, pág. 101-115.

8 Cf. PARRon, A.: La Guerra Civil a Eivissa i Formentera (1936-1939), Documenta Balear:
} Palma 2000. 
por la administración franquista9 ${ }^{9}$. Aún así, habría que distinguir entre la situación económica vivida por las islas en los años de la inmediata postguerra, cuando la crisis industrial y la penuria de las condiciones de vida alcanzaron en algunos momentos proporciones dramáticas, y la evolución de la segunda mitad de los cuarenta, en los que, a pesar de la persistencia de las dificultades, ya se comenzaron a notar señales de franca recuperación.

La industria fue, sin duda, el sector más afectado por la crisis. Ésta se debió a los problemas de producción causados por la insuficiencia e irregularidad de los suministros energéticos —en 1942 las fábricas mallorquinas recibían únicamente cuatro horas de electricidad diarias--, a la drástica limitación de las importaciones de materias primas, y al hundimiento de la demanda provocada por la pérdida de los mercados exteriores y la caída del consumo interno (ver cuadro 2$)^{10}$. No fue mucho más brillante la evolución del resto de los sectores económicos. La agricultura padeció un estancamiento de la producción - especialmente notoria en el caso del cereal, que en 1947 se situaba en un $60 \%$ de la existente antes de la guerra- debido a la falta de abonos, a la desincentivación de la producción producida por la demagógica política agraria de precios controlados, y a la reducción de la demanda exterior de frutos secos y cítricos (ver cuadro 1). La ganadería y la avicultura se vieron afectadas por la falta de piensos, de tal manera que la cabaña porcina pasó de 168.389 cabezas a 54.127 entre 1940 y 1950 , y el número de aves se redujo de dos millones a medio millón entre 1936 y 1943. El comercio y el transporte quedaron en buena parte paralizados debido a las restricciones de combustible. Finalmente, el turismo - que en la primera mitad de los años treinta se había convertido en uno de los principales motores del desarrollo económico insular- desapareció prácticamente en 1936, si bien es cierto que desde mediados de los años cuarenta inició una considerable recuperación, basada principalmente en visitantes españoles ${ }^{11}$.

9 No deja de ser significativo -pese a las reservas que merecen sin duda las estadísticas relativas a la década de los cuarenta- que entre 1940 y 1950 las Baleares fueran la zona del Estado que tuvo un menor crecimiento del Producto Interior Bruto; en concreto un $0,41 \%$ frente a una media estatal de un 1,98\% (CATALAN, J.: La economía española y la Segunda Guerra Mundial, pág. 35-40).

10 Cf., también, el gráfico sobre la evolución de la industria mallorquina del calzado entre 1937 y 1945 recogido por MIRANDA ENCARNACIÓN, J.A.: «La industria del calzado española en la posguerra: los efectos del intervencionismo sobre una industria de bienes de consumo", Revista de Historia Económica año XII - no 2 (primavera - verano de 1994), pág. 321.

11 Me limito a resumir rápidamente cuestiones que ya he tratado en mis trabajos ««Els anys de la fam». Una aproximació a l'economia mallorquina durant la postguerra (1939-1951)»; L'economia balear (1929-1959); «Crisis económica y discriminación territorial en el primer franquismo. El caso de las Baleares", en Tiempos de silencio. Actas del IV Encuentro de Investigadores del Franquismo, Universitat de València - FEIS, Valencia: 1999, pág. 502-507; y «De l'època de l'autarquia a l'expansió turística (1939-1960)" en AA.DD., El segle XX a les Illes Balears. Estudis $i$ cronologia, Cort, Palma: 2000, pág. 181-217. Cf., también, MANERA, C.: «Primeras notas sobre la industria de Mallorca a las puertas del turismo de masas (1940-1960)» en Doctor Jordi Nadal. La industrialització i el desenvolupament econòmic d'Espanya, Universitat de Barcelona, Barcelona: 1999, vol. II, pág. 1546-1564; id., 
CUADRO 1. PRODUCCIÓN AGRíCOLA EN LAS BALEARES (1931-1947). BASE 1931-1935 (=100)

\begin{tabular}{|l|c|r|r|r|}
\cline { 2 - 5 } \multicolumn{1}{c|}{} & PROMEDIO 1931-35 & 1940 & 1945 & 1947 \\
\hline Arroz & 100 & 80,3 & 76,6 & 67,8 \\
\hline Avena & 100 & 68,5 & 56,1 & 60,6 \\
\hline Cebada & 100 & 87,4 & 68,0 & 69,7 \\
\hline Maíz & 100 & 523,9 & 522,2 & 453,3 \\
\hline Trigo & 100 & 69,1 & 42,7 & 60,7 \\
\hline Guisantes & 100 & 65,5 & 44,4 & 74,3 \\
\hline Habas & 100 & 50,3 & 19,2 & 40,0 \\
\hline Judías & 100 & 38,3 & 26,7 & 85,5 \\
\hline Lentejas & 100 & 62,7 & 106,9 & 117,6 \\
\hline Patatas & 100 & 93,9 & 98,9 & 101,9 \\
\hline
\end{tabular}

(David Ginard, ««Els anys de la fam. Una aproximació a l'economia mallorquina durant la postguerra (1939-1951)", Randa 43 (1999), pág. 143

\section{CuAdRo 2. PRODUCCIÓN DE CALZADO EN: MALLORCA (1937-1950)}

\begin{tabular}{|l|c|l|}
\cline { 2 - 3 } \multicolumn{1}{c|}{} & NÜMERO DE FABRICANTES & \multicolumn{1}{c|}{ PRODUCCIÓN } \\
\hline 1937 & 105 & 1.528 .671 \\
\hline 1938 & 200 & 20.000 diarios \\
\hline 1939 & 250 & 3.550 .000 \\
\hline 1940 & 235 & 2.500 .000 (aproximado) \\
\hline 1941 & 307 & 3.000 .000 (aproximado) \\
\hline 1943 & 270 & 2.750 .000 \\
\hline 1944 & 263 & 2.350 .000 \\
\hline 1945 & 242 & 2.200 .000 \\
\hline 1946 & 205 & 10.000 diarios \\
\hline 1948 & 228 & 15.000 diarios \\
\hline 1950 & 230 & 15.000 diarios \\
\hline
\end{tabular}

Fuente: Cámara Oficial de Comercio, Industria y Navegación de Palma de Mallorca, Memoria comercial y de trabajos. Año 1948 (Palma 1949), pág. 46; Antoni Colom, Economía balear (Palma 1950), pág. 10-11; Josep Vidal Isern, Economía mallorquina. El Comercio Exterior de Mallorca (Madrid 1948), pág. 43-50.

Història del creixement econòmic a Mallorca (1700-2000), Lleonard Muntaner Editor, Palma: 2001, pág. 300-306. 
No hay duda de que una evolución económica tan mediocre tenía que producir unos efectos inmediatos sobre las condiciones de trabajo de la clase obrera. Si durante los años bélicos Mallorca conoció prácticamente el pleno empleo, la reestructuración económica subsiguiente a la finalización de la Guerra Civil provocó un incremento considerable del paro. Una memoria elaborada en 1940 por la Diputación Provincial de las Baleares señalaba que «en las actividades industriales, el paro ha sufrido una agravación, alcanzando actualmente una cifra de 7.500 obreros de los cuales una tercera parte son mujeres. Causa muy importante del aumento del paro ha sido la desmovilización del Ejército que ba reintegrado a sus ocupaciones babituales a los que habian sido movilizados. $Y$ otro motivo es la escasez o falta absoluta de primeras materias. Así sucede en las industrias de panadería y pastelería, en la pequeña metalurgia, en las industrias químicas y en las textiles, de confección (especialmente zapatería) y también y de un modo señaladísimo en la industria botelera, que antes de la guerra babía sido una de las más voluminosas fuentes de ingresos de las Islas» ${ }^{12}$. No deja de ser significativo que, entre 1939 y 1940 , resultara incluso dificultosa la recolocación de los excombatientes franquistas, quienes teóricamente disponían de preferencia a la hora de cubrir las vacantes en las empresas ${ }^{13}$.

Sin embargo, pasados estos primeros tiempos, el paro dejó de ser, al menos sobre el papel, un problema importante en las Baleares. Nos consta, incluso, que desde los primeros años de la década se instalaron en Mallorca pequeños núcleos de inmigrantes procedentes del sur y del este de la Península, bastantes de los cuales se dedicaron a trabajar en diversas obras portuarias de cierta importancia que se llevaron a cabo en Palma. Se trataba, en parte, de personas expulsadas de sus lugares de origen por causas conectadas directa o indirectamente con la Guerra Civil: represión, miedo, destrucción del aparato productivo o regreso a las formas de dominación existentes antes de la República. ${ }^{14}$ Sin

12 «Memoria que correspondiente a 1939 interesa la Dirección General de Administración Local», Archivo General del Consell de Mallorca -AGCM- L. 11.101.

13 «Parte de la Jefatura Provincial de FET y de las JONS» (1-30 de noviembre de 1940) (Archivo General de la Administración (Alcalá de Henares), Secretaría General del Movimiento - Delegación Nacional de Provincias [AGA SGM-DNP] caja 29)). Las gestiones de la Jefatura Provincial de Falange dieron resultado, y. desde 1941 se fue asegurando la recolocación de todos los antiguos soldados franquistas, a los que se otorgaban unas determinadas cuotas en los concursos oposición; una conviocatoria de Gas y Electricidad Sociedad Anónima (GESA) correspondiente a julio de 1941 reservaba un $20 \%$ de las plazas para caballeros mutilados, un $40 \%$ para ex combatientes, un $10 \%$ para ex cautivos y un $10 \%$ para huérfanos del bando franquista. (La Almudaina (26 de julio de 1941), pág. 1).

14 Curiosamente, algunos de ellos se vieron sorprendidos, al llegar a la isla, por una situación económica que en ciertos aspectos era bastante peor a la de sus lugares de origen. L. CAPELLÀ: Mallorca i el món obrer, Moll, Palma: 1977, pág. 21-27; Junta Provincial de Ordenación EconómicoSocial de Baleares: Anteproyecto de plan económico (1947-1951), Palma: 1947, pág. 331; D. GINARD: L'oposició antifranquista $i$ els comunistes mallorquins (1939-1977), Publicacions de l'Abadia de Montserrat, Barcelona: 1998, pág. 78-79. Se podría tratar de casos similares a los que ha estudiado Ange-

Hispania, LXII/3, núm. 212 (2002) 1099-1128 
duda, por este motivo, ya en septiembre de 1939 fue prohibida la inmigración de obreros en paro procedentes de la Península ${ }^{15}$, la cual — de todos modosdebió continuar durante un tiempo. Así, por ejemplo, en enero de 1943 el Ayuntamiento de Inca (Mallorca) se quejaba al gobernador civil de Baleares de su falta de medios para sostener la inmigración procedente de Elda (País Valenciano) que se estaba produciendo recientemente hacia la ciudad ${ }^{16}$.

En todo caso, a medida que avanzaba la década el paro se fue absorbiendo. De este modo, si en 1940 había 2.400 parados en las Baleares, desde 1942 las cifras fueron descendiendo progresivamente hasta llegar a las 895 personas en 1948 (ver cuadro 3). En Menorca, entre 1940 y 1945 el número de parados pasó de 120 a $26^{17}$. Según datos correspondientes al período 1942-48, los sectores más afectados por el paro eran la metalurgia, la construcción, las industrias de confección y vestido, la hostelería, y la banca, los seguros y las oficinas. ${ }^{18}$ Diversos informes elaborados entre 1945 y 1947 coinciden en considerar que el paro real en las Baleares era prácticamente inexistente y que se limitaba básicamente a la ciudad de Palma y, en concreto, a sectores del peonaje y oficinistas poco cualificados ${ }^{19}$.

Para explicar que, a pesar de la recesión económica, no hubiese un volumen apreciable de parados en un momento en el que la emigración —salvo la que se efectuaba de manera ilegal hacia Argelia - había desaparecido en la práctica, hay que tener en cuenta que en estos años se produjo una intensificación de la utilización de mano de obra, sobre todo en la industria, que permitió resolver en parte el problema de la falta de materias primas y fuentes de energía. Por otra parte, las dificultades que la legislación laboral franquista imponía a

lina Puig para el caso de Sabadell (cf. PUIG, A.: «La Guerra Civil espanyola, una causa de l'emigració andalusa dels anys cinquanta?", Recerques 31 (1995), pág. 53-69).

15 Una nota de la Comisaría de Policía publicada en el Baleares (26 de septiembre de 1939), advertía: «Se avisa a todos los obreros forasteros que se encuentran en esta isla, que no manden a buscar a sus familiares, pues todos sin excepción (mujeres y niños) serán reembarcados inmediatamente. Igualmente se hará con cuantos obreros vengan a Mallorca en busca de Trabajo."

16 Archivo Municipal de Inca-AMI- correspondencia 1890.

17 Cámara Oficial de Comercio, Industria y Navegación de Menorca: Memoria comercial correspondiente al año 1940, Mahón: 1941, pág. 61; id., Memoria comercial correspondiente al año 1945, Mahón: 1946, pág. 13

18 Archivo Histórico del Reino de Mallorca, fondo Instituto Nacional de Estadística [AHRM, INE] caja 2. Es también significativo que el número de expedientes promovidos en aplicación del decreto de exención del pago de alquileres a los obreros en paro forzoso declinase a lo largo de la década. Así, si en 1940 fueron planteados 1.176 expedientes — de los que fueron concedidos 941 , en 1951 sólo se registraron doce - de los que once fueron aprobados- (Circular $n^{0} 19$ de la Cámara Oficial de la Propiedad Urbana de la Provincia de Baleares (junio de 1952), s. p).

19 «Parte de la Jefatura Provincial de Baleares» (1-31 de julio de 1945) (AGA SGM-DNP caja 164); «Parte de la Jefatura Provincial de Baleares» (marzo de 1946) (ibid.); Junta Provincial de Ordenación Económico-Social de Baleares: Anteproyecto de plan económico (1947-1951), op. cit., pág. 331-333. Según este último informante, la mayoría de los parados del primer grupo eran «vagos profesionales». 
las reducciones de plantilla que no estuviesen debidamente justificadas, fomentaban que las empresas mantuviesen contratados un buen número de obreros en una situación bastante precaria. Hay que tener en cuenta, además, que las estadísticas oficiales no contabilizaban como parados a los obreros que trabajaban dos o tres días a la semana, práctica muy corriente en este período debido a la irregularidad de los suministros energéticos ${ }^{20}$.

\section{CUADRO 3. El PARO EN LAS BALEARES (1940-1948)}

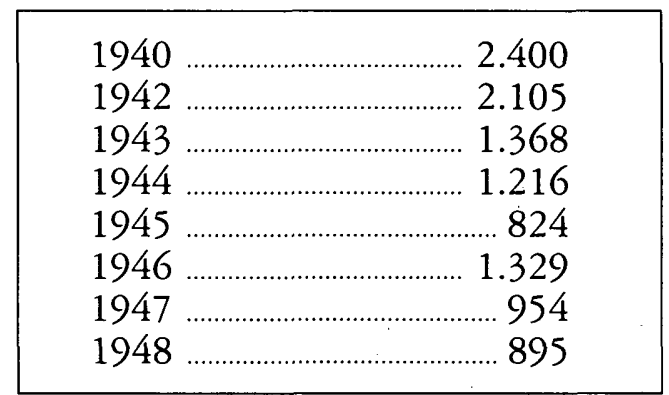

Fuente: Archivo Histórico del Reino de Mallorca [AHRM], Instituto Nacional de Industria [INE] Caja 2; Archivo General de la Administración [AGA], Secretaría General del Movimiento-Delegación Nacional de Provincias [SGM-DNP], caja 29..

Hay que tener en cuenta, por otra parte, que la implantación del régimen franquista debió suponer un cambio importante en las condiciones de trabajo de los obreros baleares. La desaparición de los sindicatos de clase y la abolición de toda posibilidad de negociación directa entre trabajadores y empresarios para la fijación de las condiciones laborales abrió las puertas a un incremento de la presión patronal que tuvo efectos inmediatos sobre la calidad de vida en las empresas. Frente a los abusos patronales, los obreros vieron reducidas sus vías de actuación a la presentación de demandas ante las magistraturas de trabajo. A título indicativo, podemos señalar que entre 1942 y 1945 la Magistratura de Trabajo de las Baleares dictó 74 sentencias favorables a los obreros y

20 Así, por ejemplo, el informe de la Jefatura Provincial de FET y de las JONS correspondiente a la quincena del 30 de julio al 15 de agosto de 1940, indica: «Estos datos no representan el aumento real que ba sufrido el número de parados, pues debido a la falta de primera materias, cueros, lana y a la restricción recientemente impuesta en el uso de la gasolina ba repercutido tan sensiblemente sobre nuestra industria quie son innumerables las empresas que se han visto precisadas a reducir los días de trabajo, por lo general a tres semanales, que el paro parcial es de una importancia enorme siendo imposible el concretar cifras aproximadas" (AGA SGM-DNP caja 29). Cf. MOLINERO, C. - YSÀs, P.: "Patria, justicia y pan», pág. 117-122.

Hispania, LXII/3, núm. 212 (2002) 1099-1128 
146 desfavorables ${ }^{21}$. Sabemos, por otra parte, que hubo fuertes presiones sobre los trabajadores para que no denunciaran a sus empresas, procedentes de la misma Delegación Provincial de Trabajo ${ }^{22}$.

$\mathrm{Si}$ bien las fuentes documentales no ofrecen, como es lógico, muchos datos que nos permitan ilustrar esta más que probable degradación de las condiciones de trabajo, se pueden señalar algunos indicios bastante claros. Nos consta, por ejemplo, que en determinados sectores industriales, como el textil, se produjo una intensificación de la utilización de mano de obra infantil ${ }^{23}$. Los accidentes de trabajo se convirtieron en un fenómeno corriente. Así, a lo largo de los años cuarenta se registró en las Baleares un promedio de mil accidentes mensuales, principalmente en la industria de la edificación —unos dos mil anuales - - pero también en la agricultura, la siderurgia, la madera y la piel. Entre 1942 y 1949 se produjeron setenta casos de muerte y sesenta y cinco de incapacidad permanente ${ }^{24}$. Además, ya durante la guerra se había establecido un incremento de la jornada laboral, que en estos años persistión ${ }^{25}$.

\section{Precios y Salarios}

No hay duda de que en las Baleares la recesión económica de la posguerra afectó de manera muy importante a la capacidad adquisitiva de las clases trabajadoras. Pese a que desde el final de la guerra el Gobierno anunció repetidamente su objetivo de rebajar los precios hasta situarlos en cifras similares a las de 1936, pronto se pudo ver cuán irreal era esta pretensión del general Franco de disciplinar a la economía como a un ejército. Hay que tener en cuenta que durante los años del conflicto bélico ya se había producido en Mallorca un incremento del coste de la vida bastante fuerte, aunque ciertamente irrelevante si lo comparamos con la hiperinflación que padeció la zona republicana (ver cuadro 4$)^{26}$.

21 AHRM, INE caja 2. Cf. BENITO DEL POZO, C.: La clase obrera asturiana durante el franquismo, siglo XXI, Madrid: 1993, pág. 349-375; Molinero, C. -YSÀS, P.: Productores disciplinados y minorias subversivas, op. cit., pág. 31-32.

22 Así, en 1940 una trabajadora expulsada de GESA que consiguió que el Tribunal Supremo declarase improcedente el despido fue forzada a renunciar a la readmisión por parte del delegado provincial de trabajo (AGA SGM-DNP caja 50).

23 EsCaRtín, J.M. - SerRAnO, A.: La dona en la Mallorca contemporània, Documenta Balear, Palma: 1997, pág. 22.

24 AHRM, INE caja 2.

25 El Día (19 de abril de 1938), pág. 3. Cf. Molinero, C. - Ysàs, P.: Productores disciplinados y minorías subversivas, pág. 21-22.

26 Datos sobre el conjunto de la España nacional indican que con una base 100 para julio de 1936, el índice de precios se situaba en 140,2 al finalizar la guerra (SÁnCHez AsiÁIN, J. Á.: «La economía en la guerra civil española (1936-1939)", en G. ANES (ed.), Historia Económica de España. Siglos XIX y XX, Galaxia Gutemberg - Círculo de Lectores, Barcelona: 1999, pág. 607). Cf., tam- 


\section{CUADRO 4. PRECIOS DE ALGUNOS ARTíCULOS DE CONSUMO EN PALMA (1936-1939)}

\begin{tabular}{|l|c|c|}
\hline & 1936 & 1939 \\
\hline Pan de trigo (kg) & 0,55 & 0,90 \\
\hline Arroz (kg) & 0,70 & 1,25 \\
\hline Garbanzos (kg) & 1,10 & 2,60 \\
\hline Lentejas (kg) & 1,15 & 1,90 \\
\hline Patatas (kg) & 0,30 & 0,45 \\
\hline Aceite (litro) & 1,90 & 3,20 \\
\hline Naranjas (kg) & 1,20 & 1,30 \\
\hline Almendras (kg) & 1,15 & 1,30 \\
\hline Carne de ternera (kg) & 3,40 & 4,75 \\
\hline Carne de cerdo (kg) & 4,75 & 7,50 \\
\hline Merluza (kg) & 4,00 & 6,00 \\
\hline Sardina (kg) & 1,00 & 1,50 \\
\hline Azúcar (kg) $(\mathrm{kg})$ & 1,80 & 2,55 \\
\hline Leche (litro) & 0,60 & 0,76 \\
\hline Carbón vegetal (kg) & 0,35 & 0,40 \\
\hline Electricidad (kw/h) & 1,00 & 1,00 \\
\hline Tejido algodón (metro) & 4,00 & 4,90 \\
\hline Calzado cuero, niño (par) & 15,50 & 21,50 \\
\hline
\end{tabular}

Fuente: AHRM, INE Caja 290

Desde 1939 el índice del coste de la vida se disparó. Datos correspondientes a Palma, indican que entre 1936 y 1949 se multiplicó por cinco. El incremento de la inflación fue especialmente elevado en el caso de los productos alimenticios, que para un índice 100 en 1936 se situaban en 632 en 1949. En cambio, durante el mismo período los salarios únicamente se triplicaron (ver cuadros 5 y 6$)^{27}$.

bién, Celestino Rey, F.: «La administración estadística del Estado: 1936-1939», Revista Fuentes Estadísticas 50 (enero de 2001), pág. 15-16.

27 Para el conjunto de España, un informe elaborado en 1942 por el Consejo Superior de Cámaras Oficiales del Comercio y de la Industria señalaba que, en el mejor de los casos, los salarios habían experimentado un aumento de entre un 40 y un 60\%, mientras que los precios oficiales se habían elevado un 300\% (MOLINERO, C.: - YSÀs, P.: Productores disciplinados y minorías subversivas, pág. 28). Asímismo, datos oficiales correspondientes a octubre de 1949 indican que el índice del coste de la vista (base 100 para julio de 1936) se situaría en 488,8, mientras que el ingreso medio de los peones de las principales ramas industriales se había multiplicado por dos (MOLINERO, C. YSÀs, P.: «Las condiciones de vida y laborales durante el primer franquismo. La subsistencia, ¿un 
CUADRO 5. RETRIBUCIONES DE LOS OBREROS BALEARES (1949)

\begin{tabular}{|c|}
\hline BASE, JULIO $1936=100$ \\
\hline 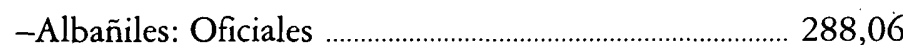 \\
\hline 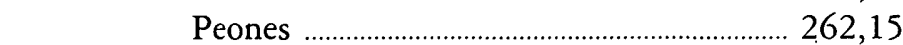 \\
\hline -Carpinteros: Oficiales \\
\hline Ayudantes ………………………….... 345,36 \\
\hline 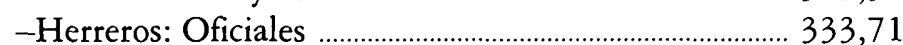 \\
\hline 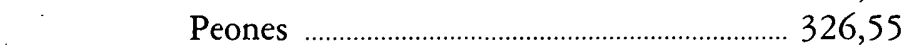 \\
\hline -Tejedores: Hombres ………………………………........ 397,07 \\
\hline 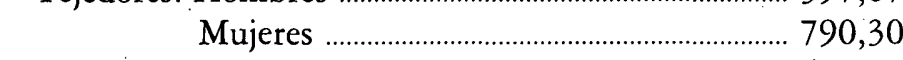 \\
\hline 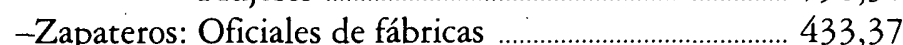 \\
\hline Oficiales de talleres ……………………...... 374,39 \\
\hline
\end{tabular}

Fuente: AHRM, INE caja 2.

\section{CUADRO 6. ÍNDICE DEL COSTE DE LA VIDA EN PALMA A PRECIOS CORRIENTES (1945-1951).}

\begin{tabular}{|l|c|c|c|c|c|c|}
\cline { 2 - 7 } \multicolumn{1}{c|}{} & \multicolumn{6}{c|}{ BASE, JULIO 1936=100 } \\
\cline { 2 - 7 } \multicolumn{1}{c|}{} & ALIMENTACIÓN & VeSTIDO & VIVIENDA & $\begin{array}{c}\text { GASTOS } \\
\text { DE CASA }\end{array}$ & $\begin{array}{c}\text { GASTOS } \\
\text { GENERALES }\end{array}$ & $\begin{array}{c}\text { ÍNDICE } \\
\text { GENERAL }\end{array}$ \\
\hline 1945 & 364,9 & 352,9 & 126,7 & 256,0 & 186,6 & 294,5 \\
\hline 1946 & 510,1 & 388,6 & 128,2 & 280,9 & 224,0 & 382,1 \\
\hline 1947 & 573,4 & 459,4 & 144,5 & 333,0 & 264,3 & 434,3 \\
\hline 1948 & 612,7 & 555,2 & 144,5 & 415,3 & 306,1 & 477,1 \\
\hline 1949 & 632,0 & 607,6 & 144,5 & 440,0 & 358,8 & 500,5 \\
\hline 1950 & 698,0 & - & 144,5 & 505,2 & 388,1 & 553,0 \\
\hline 1951 & 769,3 & 797,8 & 144,5 & 546,9 & 412,3 & 608,5 \\
\hline
\end{tabular}

Fuente: AHRM, INE Caja 3.

Informaciones relativas a la isla de Menorca indican que para una base 100 en 1936, en 1941 el salario medio se situaba en 162,5, destacando especialmente el coeficiente de aumento de los zapateros, que se situaría en 225 . En

problema político?», ponencia presentada en el VII Congreso de la Asociación de Historia Económica (Zaragoza 19-21 de septiembre del 2001), pág. 8). 
cambio, el nivel de precios en el mismo período habría pasado de 100 a $287^{28}$. Para apreciar realmente hasta que punto se hundió el poder adquisitivo de los trabajadores, hay que tener en cuenta que estas cifras se refieren exclusivamente a los precios oficiales. Dado que, para completar su dieta, la práctica totalidad de las familias debían recurrir al mercado negro, donde los precios se disparaban, es de suponer que la caída del nivel de vida debió ser realmente espectacular ${ }^{29}$. Así, por ejemplo, un informe de la Cámara de Comercio de Menorca correspondiente a 1943 denunciaba que en esa isla los jornales eran insuficientes para asegurar un mínimo de subsistencia al obrero, debido a que «el precio de los artículos, incluso los de primera necesidad, son muy elevados; ya que aún cuando los. llamados de primera necesidad son suministrados mediante cupos por la Delegación de Abastecimientos, la cantidad que de ello se reparte resulta de todo punto insuficientè: Por ello, los obreros tenían que adquirir sus artículos en el mercado negro, y así «los jornales de que disfrutan les son siempre insuficientes para con ellos cubrir las más perentoriás necesidades de sus hogares» hasta el punto de que «el.obrero en la actualidad no puede dar el rendimiento que dan en tiempos normales, con motivo de que su alimentación es de todo punto insuficiente para con ella poder realizar las labores que diariamente tiene que verificar». Estableciendo una relación entre el tipo medio de jornal, los actuales precios y lo que una familia necesitaba diariamente se había llegado a la conclusión de que «el jornal mínimo que un obrero casado y con un bijo necesitaría, sería el de 650 a 700 pesetas mensuales, pero tenemos que el jornal medio de un obrero supone tan sólo el de 300 pesetas al mes; motivo por el cual, se puede deducir por estos detalles que el rendimiento de la mano de obra, viene a suponer actualmente el del 50 por ciento con relación al de épocas normales». ${ }^{30}$

Curiosamente, y a pesar de estas cifras, los empresarios baleares achacaban en buena parte la crisis industrial a los, según ellos, excesivos costes salariales. Hay que tener en cuenta que históricamente la industria mallorquina había basado buena parte de su competitividad en el hecho de que los salarios que cobraban los obreros de la isla eran bastante inferiores a los de la Península. Es posible que la centralización de la regulación de los salarios por parte de los organismos del Ministerio de Trabajo y el fuerte incremento de cargas sociales que se produjo en estos años ocasionasen, efectivamente, un incremento de los costes de producción difícil de sobrellevar. ${ }^{31}$ Respecto a esta última cuestión, hay que tener en cuenta que durante este período aumentó mucho la impor-

\footnotetext{
28 Cámara Oficial de Comercio, Industria y Navegación de Menorca: Memoria comercial cơrrespondiente al año 1941, Mahón: 1942, pág. 51-52.

29 Nos consta, por otra parte, que el salario de las mujeres era muy inferior al de los hombres. Así, por ejemplo, se situaba en torno al $70 \%$ en el caso de la agricultura (AHRM, INE caja 2)

30 Cámara Oficial de Comercio, Industria y Navegación de Menorca: Memoria comercial correspondiente al año 1943, Mahón: 1944, pág. 63.

31 Junta Provincial de Ordenación Económico-Social de Baleares: Anteproyecto de plan económico (1947-1951), op. cit., pág. 315-316; Cámara Oficial de Comercio, Industria y Navegación de Palma de Mallorca: Memoria comercial y de trabajos, Palma: 1947, pág. 66.
}

Hispania, LXII/3, núm. 212 (2002) 1099-1128 
tancia de algunas formas de retribución tales como los pluses de carestía de la vida y las aportaciones sociales. Según datos procedentes del Instituto Nacional de Estadística, si en 1936 las aportaciones sociales representaban un 16,26\% respecto al salario medio de un oficial albañil de las Baleares, en 1949 ya representaban un $100,41 \%$. Un estudio realizado sobre la evolución del salario en las fábricas de calzado entre 1936 y 1946 indicaba que pese a que el jornal base únicamente se había doblado, el coste total prácticamente se había multiplicado por cuatro (ver cuadro 7)..$^{32} \cdots$

\section{CUADRO 7. JORNALES Y CARGAS SOCIACLES EN LAS FÁBRICAS DE CALZADO DE LAS BALEARES (1936-1946).}

Fuente: «Información sobre salarios y cargas sociales en la industria», Archịo de la Cámara de Comercio, Industria y Navegación de Mallorca e Ibiza, 1. 2354.

\section{RACIONAMIENTO, CONSUMO Y ESTRAPERLO}

Como ya hemos indicado, el racionamiento dé productos básicos, vigènte entre 1939 y 1952 , constituye uno de los elementos centrales para entender las dificultades padecidas por las clases populares en estos años. De entrada, el

32 AHRM, INE caja 2; «Información sobre salariòs y cargas sociales en la industria», Archivo de lä Cámara de Comercio, Industria y Navegación de Mallorca e Ibiza 1. 2354. 
racionamiento tenía como objetivo asegurar que los escasos alimentos disponibles tuvieran una distribución equitativa. En la práctica, sin embargo, la corrupción omnipresente en la España del primer franquismo condujo a que se generasen toda una serie de problemas añadidos que acentuaron las diferencias sociales entre una minoría que se enriqueció gracias a la práctica del estraperlo y una mayoría que apenas podía asegurarse una alimentación básica ${ }^{33}$.

El régimen de racionamiento distinguía tres grandes categorías de cartillas -inicialmente de carácter familiar y más tarde individuales - en función de la capacidad adquisitiva de los titulares, existiendo además sistemas especiales de racionamiento para determinadas profesiones, como los mineros, o para los niños menores de dos años (éste fue establecido en 1942 e incluía cantidades determinadas de leche, azúcar, harina, aceite y jabón) ${ }^{34}$. Así, en 1949 había 347.372 cartillas de racionamiento inscritas en Mallorca, de las que un 87,3\% correspondían a la categoría más modesta (ver cuadro 8 ).

\section{CUADRO 8. CARTILLAS DE RACIONAMIENTO INSCRITAS EN MALLORCA (31 DE DICIEMBRE DE 1949)}

\begin{tabular}{|l|c|r|r|r|r|}
\cline { 2 - 6 } \multicolumn{1}{c|}{} & INFANTILES & $\begin{array}{c}1^{\mathrm{a}} \\
\text { CATEGORÍA }\end{array}$ & $\begin{array}{c}2^{\mathrm{a}} \\
\text { CATEGORÍA }\end{array}$ & $\begin{array}{c}3^{\mathrm{a}} \\
\text { CATEGORÍA }\end{array}$ & TOTAL \\
\hline Municipios urbanos & 5.940 & 6.796 & 14.441 & 180.014 & 207.191 \\
\hline $\begin{array}{l}\text { Municipios } \\
\text { industriales }\end{array}$ & 369 & 186 & 685 & 9.916 & 11.156 \\
\hline Municipios rurales & 2.962 & 1.575 & 9.872 & 96.690 & 111.099 \\
\hline Colectividades & 1 & - & 8 & 5.129 & 5.138 \\
\hline $\begin{array}{l}\text { Economatos } \\
\text { preferentes }\end{array}$ & 131 & - & - & 2.921 & 3.052 \\
\hline Id. no preferentes & 434 & 249 & 1.046 & 7.275 & 9.004 \\
\hline Pescadores & - & - & - & 732 & 732 \\
\hline Totales & $\mathbf{9 . 8 3 7}$ & $\mathbf{8 . 8 0 6}$ & $\mathbf{2 6 . 0 5 2}$ & 302.677 & 347.372 \\
\hline
\end{tabular}

Fuente: Archivo Histórico del Reino de Mallorca, INE caja 2.

No hay duda de que las cantidades distribuidas por racionamiento resultaban, en general, insuficientes. Así, por ejemplo, según informes de Falange, entre enero y mayo de 1941 los repartos en las Baleares se habían limitado a 3,200 $\mathrm{kg}$ de arroz, 0,825 $\mathrm{kg}$ de azúcar, 0,250 $\mathrm{kg}$ de aceite, 2,200 $\mathrm{kg}$ de alubias, 1,150

33 Cf. MOLINERO, C. - YSÀs, P.: «Las condiciones de vida y laborales durante el primer franquismo. La subsistencia, ¿un problema político?», ponencia presentada en el VII Congreso de la Asociación de Historia Económica (Zaragoza 19-21 de septiembre del 2001), págs. 9-12.

34 La Almudaina (13 de enero de 1942), pág. 1. 
$\mathrm{kg}$ de garbanzos y $0,350 \mathrm{~kg}$ de bacalao. Las distribuciones efectuadas durante todo el mes de septiembre de 1941 - consistentes en un cuarto de litro de aceite, 250 gramos de azúcar y 500 gramos de judías-, permitían únicamente asegurar la alimentación para dos o tres días. Por otra parte, y dada la heterogénea composición de estas entregas, era corriente que con los artículos repartidos resultara prácticamente imposible elaborar ningún plato (ver cuadro 9).

\section{CUADRO 9. ARTÍCULOS DE CONSUMO RACIONADOS DISTRIBUIDOS POR PERSONA Y A PRECIO DE TASA EN LAS BALEARES (ABRIL DE 1942).}

\begin{tabular}{|l|c|c|}
\hline \multicolumn{1}{|c|}{ ARTÍ́CULO } & $\begin{array}{c}\text { CANTIDAD REPARTIDA } \\
\text { POR PERSONA }\end{array}$ & PRECIO \\
\hline Azúcar & $0,25 \mathrm{~kg}$ & $3,2 / \mathrm{kg}$ \\
\hline Aceite & $\left(2^{\mathrm{a}}\right) 0,25$ & $14,4 / 1$ \\
\hline Aceite & $\left(1^{\mathrm{a}}\right) 0,25$ & $14,8 / 1$ \\
\hline Garbanzos & $0,25 \mathrm{~kg}$ & $2,2 / \mathrm{kg}$ \\
\hline Arroz & $0,25 \mathrm{~kg}$ & $1,8 / \mathrm{kg}$ \\
\hline Café & $0,1 \mathrm{~kg}$ & $23,25 / \mathrm{kg}$ \\
\hline Patatas & $0,5 \mathrm{~kg}$ & $0,9 / \mathrm{kg}$ \\
\hline
\end{tabular}

Fuente: Archivo Histórico del Reino de Mallorca, INE caja 290.

Es lógico, por tanto, que la práctica totalidad de la población tuviera que recurrir a la adquisición de productos en el mercado negro, donde los precios eran mucho más elevados que en el mercado oficial. Así, datos correspondientes a 1946 nos indican que en Palma un litro de aceite de oliva se pagaba a 5,4 pesetas en el mercado oficial y a 50 pesetas en el mercado negro. Las diferencias eran también muy considerables en el caso de otros productos básicos, como el arroz, el pan o el azúcar, cuyos precios en el mercado clandestino eran entre tres y seis veces superiores a los del oficial (ver cuadro 10).

\section{CuAdro 10. Precios Oficiales y extraoficiales en Palma (1946)}

\begin{tabular}{|l|c|c|c|}
\cline { 2 - 4 } \multicolumn{1}{c|}{} & UNIDAD & PRECIOS OFICIALES & PRECIOS EXTRAOFICIALES \\
\hline Carbón cok & $\mathrm{kg}$. & 0,40 & 1,00 \\
\hline Id. vegetal & $\mathrm{kg}$. & 1,05 & 1,04 \\
\hline Gas alumbrado & $\mathrm{m}^{3}$ & 1,50 & - \\
\hline $\begin{array}{l}\text { Fluido eléctrico } \\
\text { (con impuestos) }\end{array}$ & $\mathrm{kw} / \mathrm{h}$ & 1,38 & 1,50
\end{tabular}




\begin{tabular}{|c|c|c|c|}
\hline$\therefore \quad \cdots \quad \cdots$ & UNIDAD & PRECIOS OFICIALES & PRECIOS EXTRAOFICIALES \\
\hline Jabón común & $\mathrm{kg}$. & 4,00 & 14,00 \\
\hline Lejía & litro. & 1,05 & - \\
\hline Acceite de oliva & litro. & 5,40 & 50,00 \\
\hline Arroź & $\mathrm{kg}$. & 3,00 & 18,00 \\
\hline Azúcar (blanquilla) & litro & 5,50 & 50,00 \\
\hline Bacalao $\quad$ & litro & 8,00 & 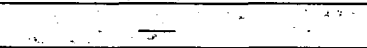 \\
\hline Café & litro $\therefore$ & 23,20 & 65,00 \\
\hline Chocolate (familiar) & libra & 4,00 & 10,00 \\
\hline Garbanzos & $\mathrm{kg}$ & 5,00 & 8,00 \\
\hline Judias secas & $\mathrm{kg} . \ldots$ & 5,50 & 7,00 \\
\hline Lentejas & $\mathrm{kg}$ & 5,00 & 8,00 \\
\hline Pastapara sopa & $\mathrm{kg}$ & 5,00 & 14,00 \\
\hline Sal comun & $\mathrm{kg}$ & $0,60 \ldots$ & $\frac{1}{2} \quad \cdots$ \\
\hline Carne de vaca $\left(1^{a}\right)$ & $\mathrm{kg}$ & 20,20 & 28,00 \\
\hline Carne de cordero & $\mathrm{kg}$. & 15,35 & 22,00 \\
\hline Carné de cerdo. & $\mathrm{kg}$. & - & 45,00 \\
\hline Tocino & $\mathrm{kg}$. & 12,00 & 40,00 \\
\hline Leche de vaca & litro & $1 ; 90$ & 2,50 \\
\hline Manteca de vaca & $\mathrm{kg}$ & $\div \quad$ & - \\
\hline Manteca de cerdo & kg. & 15,50 & 45,00 \\
\hline Huevos & docena & 20,00 & - \\
\hline Merluza & $\mathrm{kg}$ & 12,00 & $.15,00$ \\
\hline Besúgo & $\mathrm{kg}$. & 6,45 & 9,00 \\
\hline Sạdina & $\mathrm{kg}$ & 4,50 & 7,00 \\
\hline Harina de trigo & $\mathrm{kg}$. & 2,10 & 79,50 \\
\hline Pan & $\mathrm{kg}$. & 2,75 & 7,50 \\
\hline Acelgas & kg. & 0,80 & - \\
\hline Cebollas & kg. & 0,65 & 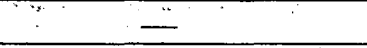 \\
\hline Tomate fresco & $\mathrm{kg}$ & 1,80 & - \\
\hline Patatas & $\mathrm{kg}$ & 1,95 & 4,00 \\
\hline Uvas $^{2}$ & $\mathrm{~kg}$ & 4,00 & - \\
\hline Malta & $\mathrm{kg}$. & $7,50^{\circ}$ & 9,00 \\
\hline Cerveza: & litro. & 5,20 & $\ldots$ \\
\hline Vino tinte común & litro & 2,00 & 3,50 \\
\hline
\end{tabular}

Fuente: «Expediente: Informe sobre situación económica. Año 1946», Archivo de la Cámara de Comercio, Industria y Navegaçión de Mallorca, Ibiza y Formentera, sin clasificar.

No ha de sorprender, por tanto, que desde comienzos de los años cuarenta el hambre hiciese su aparición en las islass, siendo la situación más grave en la ciudad de Palma y en las islas menores que en la zona rural de Mạllorca. Los

Hispania,LXII/3, núm. 212(2002) 1099-1128 
informes quincenales y mensuales que la Jefatura. Provincial de las Baleares de Falange Española Tradicionalista y de las JONS envió a la Delegación Nacional de Provincias, al menos desde junio de $1940, \mathrm{y}$ que se conservan en el $\mathrm{Ar}-$ chivo General de la Administración, en Alcalá de Henares, son una fuente excepcional para estudiar las enormes dificultades económicas que padeció Mallorca durante los años cuarenta y la falta de interés de la Administración central para solucionar este problema. En principio, pensamos que hay que otorgar una especial credibilidad a estos documentos, dada su procedencia oficial. De todos modos, no se puede descartar que en alguna de las comunícaciones los responsables baleares del Movimiento exagerăsen la gravedad de la situación, bien por disputas internas entre làs autoridades locales, bien para conseguir una especial atención de la Administràción ${ }^{35}$.

Estos informes nos indican que la falta de subsistencias fue especialmente grave entre 1940 y 1941, y que, después de una ligera recuperación, se volvió a pasar por una fase crítica entre 1945 y 1946, mejorando de nuevo en los últimos años de la década ${ }^{36}$. Así, el 30 de enero de 1941, el jefe provincial de FET y de las JONS de las Baleares, Canuto Boloqui, envió al secretario general del Movimiento un interésante informe en el que exponía que la situación de las Baleares era insostenible por la falta de alimentos, hastà èl punto de que se carécía por completo de pan, patatas, moniatos, arroz; sopa, judías, garbanzos, lentejas, purés, azúcar, chocolate, café, leche condensada, mantéca, margarina y tocino. El consumo estaba abierto únicamente a algunos productos como frutas, verduras y algo de carne; todos ellos a un precio tan elevado que eran inasequibles a familias de clase obrera y media. De este modo, muchas familias mòdestas șe nütrían únicamente de naranjas y el $40 \%$ de los niños presentaba síntomas de tuberculosis. Según Boloqui, la situación era tan grave que là población se desentendía completamente de los problemas políticos y centraba su atención en la subsistericia. Eran muy frecuentes, por otra parte, las expediciones de familias de Palma que marchaban hacia las zonas rurales para conseguir

.35 Sobre la utilidad de los "partes mensuales» como fuentes para la investigación histórica, Cf. F. Sevillano Caléro, Ecos de papel. La opinión de los españoles en la época de Franco, Biblioteca Nueva, Madrid: 2000, pág. 24; MORENO FONSERET, R. - SÁNCHEZ RECIO, G.: «Los partes mensuales: la información interna de FET y de las JONS y el control político de la sociedad española» en $I$ Encuentro de Investigadores del Franquismo, Universitat Autònoma de Barcelona - CONC, Barcelona: 1992, págs. 66-69. Sabemos que en algunà otra provincia, como Valencia, las autoridades falangistas también se quejaban de padecer una cierta discriminación en la distribución de alimentos (GÓMEZ RODÄ, A.: "Actitudes y percepciones de la posguerra en Valencia: Informes de Falange, póliciales, diplomáticos y del Partido Comunista», en SAZ, I.: - GÓM̈̈Z RODA, A.: El franquismo en Valencia. Formas de vida y actitudes sociales en la posguerra, Episteme, Valencia: 1999, pág. 85).

36 Para el conjunto español, Carme Molinè y Pere Ysàs parecen habêr llegado a las mismas conclusiones (MOLINERO C.: - YSÀS, P.: «Las condiciones de vida y laborales durante el primer franquismo. La subsistericia, ¿un problema político?», ponencia presentada en el VII Congreso de la Asociăción de Historia Económica (Zaragoza 19-21 de septiembre del 2001), pág. 9) 
algún tipo de alimento ${ }^{37}$. Tres meses más tarde la denuncia era incluso más contundente:

«La población no tiene con que comer. Prueba de ello es el índice de repartos con arreglo a cartilla de racionamiento que acusa entregas escasamente mensuales de 150 a 200 gramos de legumbres por persona. Desde el 21 de diciembre del pasado año ha sido únicamente distribuido un cuarto de litro de aceite por persona; de azúcar se han hecho dos entregas de unos 125 gramos cada una, y el arroz hace meses que no se conoce. Igualmente se carece por completo de manteca, margarina y de otros elementos básicos para la condimentación. El pan, total o parcialmente elaborado a base de maíz, no constituye tampoco una base de alimentación, atendida la exigua ración que del mismo se distribuye. De esta forma, contando con la falta de carne, con los precios elevadísimos de los huevos y del pescado, con la absoluta carencia de patatas, moniatos, arroz, sopa, chocolate, legumbres, azúcar, etc, se ha llegado al límite resistencia. La depauperación se ceba en forma ostensible en las fábricas, talleres y construcciones, dándose el caso frecuente de cesar en el trabajo, desplomados en el suelo por falta de alimentación. Todos los días se presentan en casas particulares muchachos famélicos y mujeres con sus hijos en brazos pidiendo algún alimento y rechazando donativos en metálico»38.

En julio del mismo año se aseguraba que «por todo lo expuesto, y como resumen, podemos decir que la gente vive de verdadero milagro y que la actual generación, de seguir así las cosas, está llamada a ser una legión de personas depauperadas y faltas de vitalidad.»39. Según los informantes de Falange, la falta de subsistencias en las Baleares era mucho peor que en otras zonas de España, y había provocado un descontento social creciente ${ }^{40}$. Si en este mismo escrito se sostenía que «en $\mathrm{Ma}$ llorca se aprecia con verdadero dolor lo que ya viene siendo más que insolidaridad de la Península con la Isla, al punto que hay quien lo considera enemistad manifiesta», todavía en 1946 se afirmaba que «la cuestión subsistencias va empeorando diariamente, lo que da lugar a fuerte malestar y a un descontento tan enorme que, en sus diatribas y maldiciones, no respeta ya ni al caudillo, contra el cual se habla y se murmura mucho alegando que si él quisiera no ocurriría lo que ocurriendo está; dícese que se trata a estas islas peor que si fueran una colonia». ${ }^{41}$

37 AGA SGM-DNP caja 29. Sobre estas expediciones, cf. Jaume Armengol i Coll, «Entrevista a Guillem Far», Inca Revista 15 (enero-febrero de 1989), págs. 20-21.

38 Informe firmado por el jefe provincial de FET y de las JONS de las Baleares José Vich (26 de abril de 1941).

39 AGA SGM-DNP caja 29.

40 El propio órgano falangista Aquí Estamos denunciaba en 1942 que: «El problema es de subsistencias. He aquí de lo que se babla en corros y corrillos [...]. Hay quien se aprovecha de las situaciones anormales para bacer su política y captar adeptos para cierta doctrina de fondo subversivo.» (Aquí Estamos 74 (enero de 1942), s.p.).

41 AGA SGM-DNP caja 64. Curiosamente estas informaciones coinciden con las declaraciones que en febrero de 1944 hizo al órgano del PCE en México España Popular, un mallorquín recientemente llegado a este país. En ellas se afirmaba que «en Mallorca se sufre, si esto es posible, más hambre 
Entre los productos que escasearon especialmente en las islas a lo largo de prácticamente toda la década hay que destacar el pan, el aceite, el azúcar y el arroz. En julio de 1940, el jefe provincial de FET y de las JONS reconocía que «es muy frecuente la carencia absoluta de pan en buen número de barriadas de Palma, con la consiguiente indignación de los que tienen derecho a ración extraordinaria de pan y cuya no muy elevada retribución no les permite otra alimentación que no sea la a base de dicho artículo [...]. La inmensa mayoría de familias obreras se quejan amargamente de la situación, pues debido a que los salarios no ban sufrido un aumento equivalente al alza del coste de la vida y como la base de su alimentación está en el pan, les es materialmente imposible la adquisición de alimentos supletorios de dicho artículo. ${ }^{42} \mathrm{Las}$ quejas sobre la exigüidad e irregularidad de los repartos de este producto continuaron hasta bien avanzada la década. En el caso del aceite, los problemas de abastecimiento provocaban un especial descontento entre la población, por tratarse de un producto del que en teoría se disponía de una producción más que suficiente. Tal y como indicaba un informe de Falange: «Una impresión desagradable recogida es la que se refiere al suministro de aceite. La gente sufre o no sufre la escasez de pan, pero tiène comprensión para la misma. Lo que no entienden ni entenderán nunca es que falte aceite. De enero del año pasado a enero de este año se ban repartido cuatro litros por persona. De enero de este año hasta abora, ni un gramo. Como es de sobra conocido que la producción es suficiente para el consumo de toda España, y además en diversos preámbulos de disposiciones legales ba dicho repetidamente el gobierno que sobraba aceite, gran masa del pueblo y de gentes que no son del pueblo niegan todo crédito a la labor organizadora del Gobierno, citando lo del aceite como ejemplo.»43

Prueba de los cambios que se produjeron en la dieta alimenticia es que en 1945 el consumo de carne en Palma se situó en torno a un $40 \%$ del de 1936 o que la producción de leche pasó de 4.180 .217 litros en 1940 a 1.641 .787 en 1946 , de tal manera que este producto escaseó a lo largo de toda la década ${ }^{44}$. Por el contrario, algunos productos de baja calidad que hasta entonces se utili-

\footnotetext{
aún que en el resto de España. [...] Allí no hay pan más que una o dos veces por semana. Cuantos van a Barcelona vienen asombrados porque alli -donde el hambre también es atroz- reciben sin embargo raciones, insuficientes, es verdad, de pan cada dos días. Naturalmente bay que acudir a comprar aquello que puede encontrarse en los comercios. Y se encuentra usted con que aún pagando al precio de tasa, los precios son inabordables, porque un kilo de pan vale 12 pesetas, uno de azúcar 35 pesetas, un traje de tela malísima 300 pesetas, unos zapatos que duran apenas un mes, 150 a 200 pesetas. [...] Ya comprende usted que los que viven de un salario materialmente no pueden ni comer [...]. Y no es extraña esta situación, teniendo en cuenta, junto al precio de las cosas la miseria de los jornales. Los obreros muy calificados $y$ de los oficios mejor pagados, reciben un salario de 15 a 20 pesetas. Pero los jornales corrientes para la inmensa mayoría de los trabajadores oscila entre 8 y 12 pesetas. Los jóvenes reciben solo de 5 a 7 pesetas, y las mujeres, a las que se paga aún menos, solo cobran 6, 7 y 8 pesetas. " («Terror y miseria en la Isla Dorada», España Popular 176 (11 de febrero de 1944), pág. 6).

42 AGA SGM-DNP caja 29.

43 «Parte mensual de la Jefatura Provincial de Baleares» (1-28 de febrero de 1941), AGA SGM-DNP caja 29.

44 AHRM, INE caja 3; Junta Provincial de Ordenación Económico - Social de Baleares, Anteproyecto de plan económico (1947-1951), págs. 99-100.
} 
zaban principalmente para la alimentación animal pasaron a ser un ingrediente básico en la nutrición de la población isleña. Los moniatos, los higos secos, el pan de maíz, el chocolate de algarrobas..., son ejemplos de este empobrecimiento generalizado de la dieta ${ }^{45}$. También se incrementó ligeramente el consumo de pescado, que era usado como sustitutivo de la carne, si bien las deficiencias de la industria pesquera local-acrecentadas notablemente por la falta de combustible y de algunos utensilios- impidieron que el incremento de capturás alcanzase el nivel deseado. Entre 1944 y 1949, el volumen de la pesca dedicada al consumo de la población en la Lonja de Contratación de Palma pasó de 1.676 .396 kilogramos a $2.123 .685^{46}$. De manera significativa, los problemas de abastecimiento de productos básicos afectaban incluso al Ejército. Así, un informe del Estado Mayor sobre las muestras de descontento en el Ejército correspondiente a enero de 1941 indica que según una información procedente de las Baleares, "las dificultades de abastecimiento para la comida de la tropa subsisten agudizadas por la carestía de precios y por no suministrar intendencia algunos artículos que como la patata son base de las comidas» ${ }^{47}$.

La escasez de productos básicos resultaba especialmente escandalosa debido a la exposición pública de alimentos de lujo y a la publicación en la prensa locăl de noticias sobre brillantes cosechas o de anuncios sobre inminentes distribuciones de artículos, que a menudo después no se concretaban. ${ }^{48} \mathrm{El}$ informe $\mathrm{CO}^{-}$ rrespondiente à agosto de 1.941 llamába la atención, incluso, sobre los"enormes . contrastes existentes entre las condiciones de vida de las clases populares y la situación de la que gozaban los sectores privilegiados de la sociedad: "Lais personas favorecidas por la fortuna disfrutan de una vida regalada y sin escaseces puesto que con suficiente dinero pueden adquirirse toda clase de productos de pastelería, galletas de barina, y muchos otros asequibles a sus bien repletas bolsas. En cambio, los pobres tienen que limitarse a contentar el hambre viendo los escaparates. repletos de pasteles, galletas de barina, conforme rezan algunos cartelitos (éstas a 17 pesetas el $\mathrm{Kg}$. cuando no más ca-

45 Rotger BuILs, V.: Memorias de Vicente Rotger Buils, edición del autor, Palma 1994, pág. 107: «Recuerdo que en aquella época de hambre y escasez de alimentos se confeccionaba un pan de maíz de color amarillo que resultaba prácticamente incomestible. $A l$ intentar masticarlo se formaba una bola pegajosa en la boca de sabor muy parecido al del serrín. También se vendian panes de higos secos, cuyo precio dependía del peso. Algunos de sus fabricantes, de escasos escrúpulos, introducian arena en su interior con la intención de que pesasen más». La Cámara de Comercio solicitó en 1946 al Director General de la Contribución de Usos y Consumos que se excluyera del pago de tributo a los higos secos por ser «alimento que consume [...] exclusivamente el consumidor èscaso de recursos [...]. Ha sido siempre así y boy constituye para el pobre, más que nunca, un complemento con que sustituir otrồ productos elementales para su alimentación" (Archivo de la Cámara de Industria, Comercio y Navegación de Mallorca, Ibiza y Formentera, sin clasificar).

46 AHRM, INE caja 2.

47 En el mismo documento se indica que «Baleares comunica en su parte mensual que a la tropa de Ibiza se le suministra jabón desde el mes de Noviembre de 1940" (Documentos Inéditos para la Historia del Generalísimo Franco, tomo II-2, págs. 59-60): :

${ }_{48} \mathrm{Cf}$. el informe de la Jefatúra Provinciál de Baleares correspondiente a la primera quincéna de agosto de 1940 (AGA SGM-DNP caja 29).

Hispania, LX'II/3, núm: 212 (2002) 1099-1128 
ras). Terrible injusticia cuyas consecuencias serán aún más pavorosas por ir directamente contra las palabras de nuestro Caudillo: "Ni un hogar sin lumbre, ni una despensa sin pan"» 49 Esta situación también era advertida, por el cónsul británico en Mallorca, quien a finales de 1945 llamaba la atención sobre el hecho de que «mientras las tiendas estaban llenas de productos llegaban noticias de varios lugares de que la gente pasaba bambre y el racionamiento nunca había estado peor» ${ }^{50}$.

La situación de miseria provocó alteraciones del orden público a lo largo de los primeros años cuarenta. El robo de productos alimenticios (patatas, frutas, aves de corral, etc.) alcanzó unas proporciones alarmantes en 1941, principalmente en Menorca, Formentera y las zonas rurales de Mallorca. Según un informe oficial, "a consecuencia del malestar y de la difícil situación reinante, son frecuentes los casos de robo en los medios rurales, de productos agrícolas; las autoridades se esfuerzan para impedir tales bechos que son exponentes del bambre que se sufre en la casi totalidad de las casas y que, de persistir la actual falta de alimentos, hace suponer asaltos en mayor escala en detrimento de las futuras cosechas, sea cereales, hortalizas y frutas» ${ }^{51}$. Por otra parte, nos consta que se produjo un incremento de la prostitución. Un informe correspondiente al estado de la moralidad en las Baleares correspondiente a 1942 consideraba que ésta era «mala» en Palma y Mahón y «algo mejor» en Ibiza. En la capital existían 25 casas de prostitución y 506 prostitutas fichadas. Por otra parte, se señalaba que el número de niños abandonados había aumentado desde el final de la Guerra Civil. Diez años más tarde la situación no había mejorado. Se registraban 30 «casas de lenocinio» en el archipiélago y se reconocía que la carestía de la vida y la escasez de viviendas se

49 AGA SGM-DNP caja 29. Más adelante, el informe hace referencia a la mala calidad de la leche ("da verdaderas náuseas el consumirla; tanto es así que en gran número de casas prefieren no beberla»), hecho que contrastaba con la existencia en Palma de cuarenta o cincuenta establecimientos dedicados a la venta de helados, y a la negativa de la Junta de Abastecimientos a proporcionar azúcar incluso para elaborar los biberones de los bebés, mientras se distribuía azúcar regularmente a las pastelerías y otros establecimientos similares. A finales de julio, el gobernador civil había prohibido la fabricación de queso y mantequilla elaborados con leche de vaca (La Almudaina (29 de julio de 1941), pág. 1). En 1942 fue prohibida «la ostentación en escaparates de artículos alimenticios» (Alimentación Nacional 10 (5 de agosto de 1942), pág. 10). Cf. «Terror y miseria en la Isla Dorada», España Popular 176 (11 de febrero de 1944), pág. 6.

50 CAZORla SÁNCHEZ, A.: Las politicas de la victoria. La consolidación del Nuevo Estado franquista, Marcial Pons, Madrid: 2000, pág. 92. Señalemos, de paso, que otro informe del mismo representante diplomático correspondiente a marzo de 1946 indicaba que la situación alimentaria era la peor desde el final de la guerra y que la degradación de las condiciones de vida en la isla habían llegado hasta el punto de que los valores «están siendo lentamente sustituidos por el materialismo, el escepticismo, el sarcasmo bacia la tradición y el trabajo bien becho, mientras que la recompensa monetaria se está convirtiendo en la única consideración» (ibid., pág. 230).

51 «Parte de la Jefatura Provincial de Baleares» (1-31 de enero de 1941) (AGA SGM-DNP caja 29); «Parte de la Jefatura Provincial de Baleares» (1-28 de febrero de 1941) (ibid). La prensa local se hizo eco del fuerte aumento de la delincuencia registrado en Palma ( $U$ Una súplica de los vigilantes nocturnos al vecindario de Palma», Baleares (13 de octubre de 1946), pág. 3). 
hallaban entre los factores principales que ocasionaban el incremento de la prostitución y la inmoralidad ${ }^{52}$.

Como ya hemos indicado, el racionamiento de productos, y la extrema escasez de alimentos favorecieron la aparición del estraperlo, término que indicaba toda una serie de actividades ilícitas como el acaparamiento y la venta fraudulenta de productos, las adulteraciones de alimentos y el tráfico de cartillas de racionamiento. El estraperlo de la posguerra española presentó unas características peculiares debido a su duración, amplitud, profundidad, generalización y aceptación social como fenómeno inevitable, y tuvo como consecuencia una reducción de las cantidades intercambiadas en el comercio regular, una elevación de los precios y un deterioramiento de la calidad ${ }^{53}$. Aunque fue un fenómeno generalizado en todo el Estado, parece que tuvo una especial incidencia en las Baleares, donde la carestía de bienes de consumo era especialmente grave y, además, habían estado muy extendidas tradicionalmente las actividades económicas ilegales como el contrabando ${ }^{54}$. La memoria popular recuerda especialmente las expediciones de palmesanos que se trasladaban en tren a la localidad agrícola de Sa Pobla para adquirir alimentos ilegalmente. En el viaje de regreso, y poco antes de llegar a la estación de Palma, los compradores lanzaban los productos por la ventana y allí eran recogidos por cómplices que se encargaban después de su venta clandestina ${ }^{55}$.

El régimen franquista intentó transmitir a la opinión pública su rechazo absoluto a la corrupción económica y su compromiso en la lucha contra el estraperlo ${ }^{56}$ De hecho, la prensa de la época recogía semanalmente amplias listas en las que se detallaban las sanciones económicas impuestas a los infractores en materia de abastecimientos. Así, por ejemplo, la venta clandestina de productos básicos (patatas, alubias, trigo, aceite, manteca...) podía ser sancionada con multas de entre 4.000 y 10.000 pesetas; la ocultación de la producción, con 75.000 pesetas; y la tenencia de dos cartillas de racionamiento, con 1.000 pesetas. Habitualmente estas medidas iban acompañadas de la incautación de la mercancía y, en su caso, del cierre del establecimiento. En los casos más graves o cuando el infractor no había satisfecho una pena impuesta anteriormente, se po-

52 Citado por Roura: A.: Mujeres para después de una guerra. Informes sobre moralidad y prostitución en la posguerra española, Flor del Viento, Barcelona: 1998, págs. 167-169. Cf. «Terror y miseria en la Isla Dorada", España Popular 176 (11 de febrero de 1944), pág. 6.

s3 Cf., en general, BARCiela, C.: «La España del «estraperlo» «, en GarCía Delgado, J. L.: El primer franquismo. España durante la segunda guerra mundial, op. cit., pág. 105-122; id., «Franquismo y corrupción económica», Historia Social 30 (1998), págs. 83-96.

s4 Cf. Burguera I VIDAL, J.: El contraban i la seva influència sobre la població de la zona sud de Mallorca, edición del autor, Ses Salines: 1988, págs. 49-50.

55 Entrevista a Jaume Rebassa Romer (Palma, 15 de mayo de 1996); RotGer BUILS, V.: Memorias de Vicente Rotger Buils, op. cit., pág. 108; La Almudaina (9 de julio de 1941), pág. 1.

56 Ver, por ejemplo, el editorial del Baleares correspondiente al 21 de octubre de 1939 o el artículo «Campaña contra el straperlismo», Menorca (18 de septiembre de 1946), pág. 3. 
día llegar a disponer su internamiento en un batallón de trabajadores. Todo parece indicar que estas sanciones tuvieron, en general, una limitada efectividad ${ }^{57}$.

En cualquier caso, no hay ninguna duda de que el estraperlo representó una actividad sumamente lucrativa que permitió acumular algunas grandes fortunas - base de posteriores inversiones turísticas-y que se llevaba a cabo con la colaboración de altos funcionarios y autoridades del régimen. El informe de la Jefatura Provincial del Movimiento correspondiente a la quincena del 29 de junio al 13 de julio de 1940 reconocía que «el «straperlo» continúa no obstante las denuncias que se vienen haciendo como consecuencia de la fiscalización del Partido, debiendo atribuirse dicha anormalidad a no ser castigados por la autoridad correspondiente los autores de esta infracción de la Ley" ${ }^{58}$. Quince días más tarde, se denunciaba que «la cuestión sobre el lamado «straperlo» ba alcanzado tal desarrollo, principalmente en Mabón, debido a la negligencia de la autoridad gubernativa, que un camarada nuestro, vieja guardia, emitió un artículo en un periódico local, "Hondero», lamentándose de dicha situación. Dicho camarada, a pesar de las múltiples denuncias bechas al Delegado Gubernativo, no ha sido atendido en lo más mínimo" "s9, y en julio de 1941 se criticaba la completa pasividad de las fuerzas de la policía en la represión de la venta de artículos a precios abusivos ${ }^{60}$.

Todo indica que las responsabilidades llegaron hasta la máxima autoridad provincial, de tal manera que la práctica totalidad de los gobernadores civiles que se fueron sucediendo durante los años cuarenta en las Baleares fueron acusados de ineptitud, cuando no de complicidad con los estraperlistas ${ }^{61}$. A lo lar-

57 En el informe de la Jefatura Provincial de las Baleares de FET y de las JONS correspondiente a junio de 1941 se denuncia que «siendo la sanción a los que se dedican al «straperlo» solamente de una simple multa ello sirve tan solo para fomentarlo» (AGA SGM-DNP caja 29).

58 AGA SGM-DNP caja 29.

59 «Parte de la Jefatura Provincial de Baleares» (14 al 29 de julio del 1940) (AGA SGM-DNP caja 29). En el informe del 30 de julio al 13 de agosto siguientes se insiste: «Continúa el «straperlo» tomando incremento sin que se vean atendidas por la autoridad gubernativa las denuncias que le son transmitidas".

60 AGA SGM-DNP caja 29. En enero de 1941 se anunció que habían sido destituidos y severamente sancionados dos alcaldes de pueblos mallorquines «por no ajustarse en su actuación a las normas dadas por la superioridad en materia de abastos» (La Almudaina (18 de enero de 1941), pág. 1). Un informe firmado el 3 de abril de 1939 por el jefe provincial de Falange Canuto Boloqui indicaba que Alcudia (Mallorca) se hallaba desabastecida de artículos básicos, siendo responsable de ello «en sus tres cuartas partes» el alcalde del pueblo, al tiempo que señalaba que «los agricultores de Mallorca con la guerra ban visto aumentados sus ingresos puesto que el valor de sus productos casi [se] ba triplicado. Díganlo sino estos payeses de Alcudia que obtienen un dineral con las bortalizas. No obstante ocultan los cereales por no vender al precio de tasa. Con fecha de boy he proporcionado tres nombres a la Guardia Civil» (AHRM, Gobierno Civil, caja 665).

61 Parece ser que la excepción a esta regla general se encontraría en el caso del futuro secretario de la Delegación Nacional de Sindicatos Fermín Sanz Orrio, quien a lo largo de 1940-41 impulsó un paquete de medidas para hacer frente a la escasez de subsistencias, si bien entre éstas se hallaban algunas tan pintorescas como la de prohibir las colas ante los establecimientos en los que se vendían los productos sujetos a racionamiento («Es indispensable terminar con el espectáculo de las colas», Baleares (19 de noviembre de 1940), pàg. 3). Por otra parte, alguna de sus iniciativas, como la de crear economatos en las fábricas, tuvo que hacer frente al rechazo de entidades económicas como la Cámara de Comercio (Archivo de la Cámara de Comercio, Industria y Navegación de Mallorca, Ibiza y Formentera, L. 2.367). 
go de 1940, los informes de Falange denunciaron la escasa pericia del gobernador civil Fernando Vázquez Ramos para gestionar eficazmente el suministro de alimentos y combatir el estraperlo - no en vano, su sustitución en octubre de aquel año fue recibida con notable satisfacción por parte de los falangistas-. ${ }^{62}$ Según el testimonio de un alto cargo que vivió de cerca estos acontecimientos, otro gobernador civil, Manuel Veglison Jornet, fue destituido y tuvo que huir a México en junio de 1945 por su relación con la adulteración de alimentos, mientras que alguno de sus principales colaboradores fue encarcelado. Parece ser que también fue clara la implicación del su sustituto José Manuel Pardo Suárez en la adulteración de la leche practicada por la empresa Lactel, hecho que tuvo incluso resonancia en la prensa de Palma ${ }^{63}$.

\section{SANIDAD, VIVIENDA, BENEFICIENCIA Y EDUCACIÓN}

Los informes de la Jefatura Provincial de Baleares de Falange acostumbraban a conceptuar como «buena» la situación sanitaria en el archipiélago. De todos modos, es evidente que la subalimentación tuvo unos efectos perniciosos en estado de salud de los isleños. Ya hemos explicado anteriormente que, según un informe oficial, en 1941 el $40 \%$ de los niños de Palma presentaban síntomas de tuberculosis. A lo largo de la década la situación continuó siendo preocupante, hasta el punto que en 1949 el Dispensario Antituberculoso de Palma tuvo que atender 23.745 casos (ver cuadro 11).

\section{CUADRO 11. SERVICIOS PRESTADOS EN EL DisPENSARIO ANTITUBERCULOSO DE PALMA (1941-1949)}

\begin{tabular}{|c|}
\hline 1941 \\
\hline $1942 \ldots$ \\
\hline 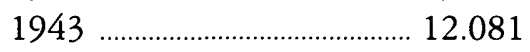 \\
\hline 1944 \\
\hline 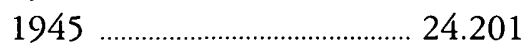 \\
\hline 1946 \\
\hline 1947 \\
\hline $1948 \ldots$ \\
\hline 1949 \\
\hline
\end{tabular}

Fuente: AHRM, INE Caja 2.

62 Cf. los partes mensuales de la Jefatura Provincial de Baleares correspondientes al 14-29 de julio de 1940 y al 14-31 de agosto de 1940 (AGA SGM-DNP caja 29).

63 «Información general de Palma de Mallorca» AGA SGM-DNP caja 164; La Almudaina (6 de octubre de 1946), pág. 6; Baleares (9 de octubre de 1946), pág. 1.

Hispania, LXII/3, núm. 212 (2002) 1099-1128 
Pero la situación de la clase trabajadora era igualmente grave por lo que respecta a otros aspectos, como la vivienda o el nivel de escolarización. En cuanto a las viviendas, hay que tener en cuenta que el ritmo de edificaciones quedó estancado en estos años debido a la falta de materiales de construcción (cemento, madera, hierro, etc.). Este hecho fue especialmente grave en el caso de ciudades como Palma o Mahón, las cuales habían sufrido un cierto impacto por los bombardeos aéreos durante la Guerra Civil. De este modo, en Mallorca se pasó de 939 edificios construidos en 1939, a sólo 677 en $1942^{64}$. El parte de la Jefatura Provincial de Baleares, correspondiente a abril de 1941, señalaba que use impone cada vez más la necesidad de emprender la construcción de viviendas protegidas a fin de eliminar una gran cantidad de casas de mísero aspecto y de condiciones higiénicas insalubres». ${ }^{65}$ Aún así, entre 1942 y 1954 se construyeron únicamente 528 viviendas protegidas en las Baleares, 240 de éstas en Palma ${ }^{66}$. Un informe de la Dirección General de Arquitectura correspondiente a 1947 calificaba de «tugurios» el $50 \%$ de las viviendas obreras del casco antiguo de Palma, mientras que un $30 \%$ eran consideradas «bubardillas» y únicamente un $20 \%$ merecían el concepto de «aceptables», al tiempo que se consideraba necesaria la construcción de unas 3.000 viviendas en la capital. ${ }^{67}$ Por otra parte, y a pesar de la política de contención de alquileres practicada por el gobierno, los precios de las casas continuaban siendo elevados, sobre todo en Palma y en las localidades industriales de las islas. ${ }^{68}$ Hay que señalar, finalmente, que la calidad de vida en estas viviendas se veía dificultada extraordinariamente por otras circunstancias, como la falta de agua potable o la interrupción e irregularidad de los suministros eléctricos - circunstancia esta última que generó una considerable alarma durante el duro invierno de $1941-69$.

Igualmente problemática era la situación de la enseñanza, tal vez una de las materias sociales que más había mejorado durante los años de la Segunda República. La recuperación del control del sistema educativo por parte de la Iglesia católica fue acompañada de una menor implicación de la administración en la creación y mantenimiento de los centros educativos. Así, por ejemplo, en el curso 1942-43 asistían 1.042 alumnos a centros privados de enseñanza secun-

64 Cámara Oficial de Comercio, Industria y Navegación de Palma de Mallorca: Memoria comercial. Año 1942, Palma: 1943, pág. 169

6s AGA SGM-DNP caja 29.

66 Delegación Provincial de Sindicatos de Baleares: I Asamblea Plenaria del Consejo Económico Sindical, Palma: 1954, págs. 217-218.

67 Junta Provincial de Ordenación Económico - Social de Baleares: Anteproyecto de plan económico (1947-1951), pág. 322

68 «Viviendas protegidas en el Molinar», La Almudaina (5 de octubre de 1941), pág. 1; Junta Provincial de Ordenación Económico - Social de Baleares: Anteproyecto de plan económico (1947-1951), pág. 323

69 «Parte de la Jefatura Provincial de Baleares» (1-31 de enero de 1941) (AGA SGM-DNP caja 29); La Almudaina (16 de enero de 1941), pág. 1. 
daria y tan sólo 740 a centros públicos. ${ }^{70} \mathrm{El}$ informe de Falange correspondiente a junio de 1941 reconocía que «la enseñanza no está atendida como debiera debido en gran parte a hallarse sin terminar gran número de escuelas graduadas de la capital, algunas de ellas a punto de serlo y solo pendientes de ligeros trabajos, cosa que no se comprende teniendo el Ayuntamiento medios para bacerlo y sin dificultades para tomar acuerdos como ocurría en tiempos de la política partidista. Este es el motivo de que pululen por la capital verdaderas bandadas de chicos harapientos que, a este paso, de pilluelos llegarán a convertirse en malhechores al no tener un freno y una disciplina escolar, moral $y$ política». Todavía en enero de 1942, el informe de Falange indicaba, respecto a la situación de la enseñanza en las Baleares: «En este aspecto debe señalarse una vez más la gran cantidad de muchachos sucios y desharrapados que pululan pidiendo limosna por las calles de nuestra ciudad en verdaderas bandadas, que constituyen un verdadero plantel de malbechores por las condiciones de vida en que se desenvuelven. Sería necesaria por elementales razones de salud pública que se procediera a la recogida de estos muchachos $y$ se les obligara a asistir a las escuelas. ${ }^{71}$ La depuración política de los maestros y profesores, la degradación de su situación laboral y de sus planes de formación, y la instrumentalización política del sistema educativo coadyuvaron en una caída del nivel de enseñanza. ${ }^{72}$

Con este panorama, no ha de sorprender que el Auxilio Social, implantado en Mallorca en enero de $1937^{73}$, alcanzara durante estos años enormes dimensiones. Así, el número de raciones suministradas por Auxilio Social en las Baleares a lo largo de 1941 alcanzó las 2.409.452, siendo 11.429 el número de personas atendidas en octubre de ese mismo año (ver cuadro 12$)^{74}$. Este número se fue reduciendo a lo largo de la década, de tal modo que en julio de 1946 era de 2.989 y en abril de 1948 tan sólo de $1.520^{75}$. La institución, que se financiaba a partir de recaudaciones diversas (ficha azul y postulaciones) y ayudas provenientes de la delegación nacional, tuvo que hacer frente a graves problemas económicos. ${ }^{76}$ No es de extrañar, por tanto, que se sucedieran las

70 Sureda, B.: L'educació a les Balears en el segle XX, Documenta Balear, Palma: 2000, pág. 30.

71 AGA SGM-DNP caja 29. El absentismo escolar continuaba siendo grave en 1946, de tal manera que el alcalde de Palma, Joan Coll Fuster, anunció la posible aplicación de sanciones (Archivo Municipal del Ayuntamiento de Palma, expediente de alcaldía 856).

72 Miró, S.: Maestros depurados en Baleares durante la Guerra Civil, Lleonard Muntaner Editor, Palma: 1998.

73 MARZO, J.: Montesión durante la pasada guerra civil 1936-1939, Palma: 1939, pág. 23. Cf. ORduÑa PradA, M.: El Auxilio Social (1936-1940). La etapa fundacional y los primeros años, Escuela Libre Editorial, Madrid: 1996.

74 AGA SGM-DNP caja 29.

75 AGA SGM-DNP caja 164.

76 En mayo de 1941 la situación financiera de la delegación provincial de Auxilio Social era considerada como «un verdadero desastre» por la Jefatura Provincial de Baleares de Falange. Dos meses más tarde, al presentar los datos de recaudación correspondientes al mes de mayo, el delegado provincial se quejaba amargamente de la escasa colaboración popular: "Quiero que experimentes lector, como lo siente esta delegación, el escozor de estas ciento cincuenta mil pesetas que nos llegan de fuera de 
amenazas de cierre. El informe de Falange correspondiente a agosto de 1941 hacía referencia a la decisión de la Delegación Nacional de suprimir una parte de los servicios (en particular el Auxilio en Frío, consistente en la distribución de alimentos que eran consumidos en los domicilios particulares): «Ha creado un serio problema en esta Provincia la supresión del Auxilio en Frío y parte de los demás. Como bemos venido diciendo, en Baleares se balla acentuada, en relación con las demás provincias de España, la falta de artículos de primera necesidad. La medida adoptada por la Delegación Nacional de Auxilio Social que, indudablemente, obedece a motivos poderosos y fundados, ba creado dolor y espanto a nuestros espiritus, puesto que representa el hambre más terrible para un número grande de asistidos. De las islas de Menorca, Ibiza y Formentera han llegado basta nosotros noticias desconsoladoras relacionadas con la orden de referencia baciéndose, desde la actual situación, pronósticos muy graves.» ${ }^{77}$

\title{
CUADRO 12. RACIONES SUMINISTRADAS POR LA DELEGACIÓN Provincial de BaLEARES De Auxilio Social (1941-49).
}

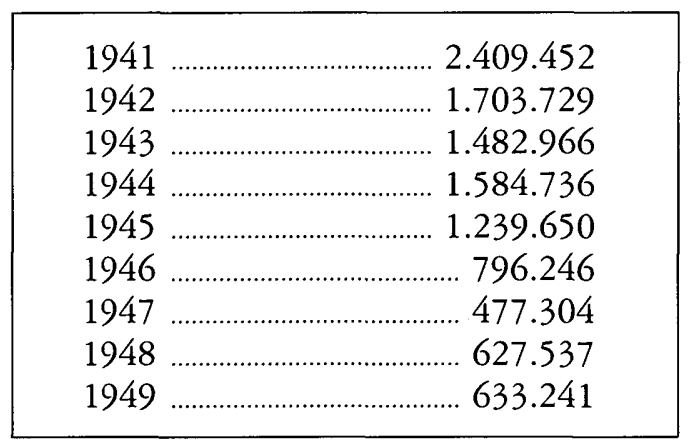

Fuente: AHRM, INE caja 2

\begin{abstract}
casa. -La aportación de esta provincia no alcanza ni siquiera para los mil novecientos cincuenta y seis niños asistidos. -La gráfica que marca vuestro esfuerzo acusa una elíptica desconsoladora que arrancando de la fecha de nuestra creación de Enero de 1937 pasa por el $1^{\circ}$ de abril de 1939 y desmaya en nuestros días" (La Almudaina (5 de julio de 1941), pág. 1).

77 Refiriéndose a la misma cuestión, un escrito de septiembre de 1941 señalaba que «como consecuencia de la aplicación de la citada orden se recibieron en esta Jefatura urgentes comunicaciones de diferentes jefaturas locales, en especial de Menorca e Ibiza, dando cuenta, en dramáticos términos, de la espantosa situación que tal resolución creaba automáticamente en la mayoría de núcleos urbanos por no presentarse a los asistidos otra solución, en su mayor parte, que perecer de bambre». Todavía en agosto de 1946, y ante el anuncio del cierre de los comedores de Menorca y de Formentera, se indicaba que «con el cierre de los comedores en las locales se ha producido un cierto malestar en Menorca y en Formentera, ya que la gran pobreza de las dos islas, da lugar a la existencia de bastantes necesidades» (AGA SGM-DNP caja 164). Datos correspondientes a 1943 indican que en Menorca se repartían medio millón de raciones anuales, asistiendo 1.149 personas a los comedores de hermandad, 302 a los infantiles y 355 al auxilio en frío ( Auxilio Social», Menorca (30 de octubre de 1943), pág. 2).
\end{abstract}


Podemos concluir, por tanto, que la derrota del bando republicano en la conflagración civil que tuvo lugar en el Estado español entre 1936 y 1939 marcó profundamente la evolución de la clase trabajadora balear en la siguiente década. A lo largo de los años cuarenta, los obreros de las islas conocieron un empeoramiento muy acentuado de sus condiciones de vida, debido a la caída del poder adquisitivo de los salarios y a la escasez y el racionamiento de los alimentos, pero también a las deficiencias que presentaban otros ámbitos de la vida cotidiana como el suministro energético, el transporte, la vivienda, la sanidad, o la escolarización. Aún así, desde mediados de los años cincuenta y gracias al formidable impacto del turismo, las Islas Baleares conocerán una mejora extraordinaria de su nivel de vida que les permitirá convertirse a principios de la década siguiente en una de las zonas con mayor bienestar social del Estado. De todos modos, muchas de las carencias acumuladas en el decenio crítico constituyeron una rémora que se dejará notar con fuerza en la sociedad isleña de la época turística. 